\title{
Digital Transformation of Spaces for Positioning of Production Enterprises in the Reproduction Cycle
}

\author{
Vladimir Kozlov \\ Department of Logistics and Supply \\ Chain Management \\ Saint Petersburg State University of \\ Economics \\ Saint Petersburg, Russia \\ nvvkkovlev@mail.ru
}

\author{
Ivan Rudkovsky \\ Department of Logistics and Supply \\ Chain Management \\ Saint Petersburg State University of \\ Economics \\ Saint Petersburg, Russia \\ logichain@mail.ru
}

\author{
Elena Tsaryova \\ Department of Logistics and Supply \\ Chain Management \\ Saint Petersburg State University of \\ Economics \\ Saint Petersburg, Russia \\ leyul@ya.ru
}

\begin{abstract}
The relevance of the study is determined by the urgent need to increase the efficiency and competitiveness of national production based on the logistics approach as an economical (all other things being equal), resource-saving, integrating approach to organizing and managing the economic activities of business units, business organizations of various systemic entities and levels in the areas of production and circulation in the conditions of the digital transformation of the economy.

The study was performed on the basis of systemic and logistic approaches using theoretical methods of structural analysis and synthesis of the content of the subject under consideration.

The study is devoted to the problem of economical organization of activities and interaction of business entities aimed at minimizing (all other things being equal) the economic gap between the commodity form of supply and the resource form of the real needs of business entities at all stages and levels of the reproduction process.

The structure and content of the logistics flow of adding value are presented with an emphasis on its two key components in this context of components - material and economic flows. The general analysis is given of the possibilities and advantages and the main trends for using digital technologies in the organizational space of production enterprises positioning as a factor in the competitive development and increasing the competitiveness of the logistics organization of the process for creation of value in the reproduction cycle structure.
\end{abstract}

Keywords - production enterprise, reproduction cycle, logistics approach, logistics flow, production networks, supply chains, digital transformation, digital technologies, "smart" technologies

\section{INTRODUCTION}

The widespread use of actively developing relevant information, in particular, digital technologies leads to significant changes both in the informational and in the whole organizational space of production enterprises, forms and tools of their interaction with partners in the process of value creation in the overall structure of the reproduction cycle. Information technologies become one of the factors of resource saving in the supply chain, which ultimately requires a clear understanding and accurate structuring of the content and organization of the logistics flow, its material and economic components.
It should be noted that the economic content of the logistics flow is not currently the subject of a wide range of studies. The same can be quoted about the logistics approach to the analysis and management of the reproduction process both in general and at individual levels of integration of the participating business entities, the main, the central one of which remains the production enterprise. In this regard, it should be noted those few publications, in particular [1-3], where these problems are studied, as well as one of the few that are devoted to the importance of strategic management of the reproductive process [4]. Despite the volume and fundamental nature of individual [2] publications, they do not focus on certain, in our opinion, important and significant economic aspects, which are the problematic subject of this article.

The directions and advantages of using digital technologies as a tool for the interaction of subjects of the reproduction process, as well as aspects of digital transformation are considered with varying degrees of detail and are presented by a fairly wide range of literature, in particular, works of domestic and foreign authors [5-12]. The trends in global competition based on digital and, generally, information technologies were considered in [13-14], the trends of digital technologies effects on logistics were considered in [15], while the issue of applying the logistics approach together with the active use of information technologies remains relevant. They require close consideration of the challenge of determining the factors and reserves of reducing the economic gap between the commodity form of supply and the resource form of the real needs of business entities at all stages and levels of the reproduction process, as well as the features of the transformation of production under the influence and based on digital technologies.

\section{MATERIALS AND METHODS}

The study was performed on the basis of systemic and logistic approaches using theoretical methods of structural analysis and synthesis of the content of the subject under consideration.

\section{RESULTS}

As a result of the performed study, the content of the transformation processes of the logistics flow for creating the value by the manufacturing enterprise was revealed; the general analysis of the possibilities and main trends of using 
the digital technologies in the organizational space of positioning a manufacturing enterprise in the structure of the reproduction cycle is presented.

\section{DISCUSSION}

The fifth technological mode being in the growth phase is characterized, inter alia, by the rapid development of information technologies and the growth of software quality. A sufficiently high dynamics of changes is a natural process of human society development offering ever new forms and technologies for organizing the interaction of subjects of the reproductive cycle - different levels, scales and positioning.

The digital technologies development, their active application without exaggeration in all areas of the economy leads to significant changes in the processes of information interaction in the structure of individual subjects of various economy sectors between participants in the supply chain and, as an integral result, in the general system of the reproduction cycle.

In this context, it should be particularly emphasized that in connection with the widespread use of digital technologies as an instrument for organizing interaction between economic systems and subsystems of various levels and scales, the adaptability of supply chains to external conditions, and that is critical to the requirements of consumers, both final and and production, which makes it possible to form a transparent information interaction between all participants.

One of the significant results of digital transformation in this context is the demanded opportunity to create an information product as a prototype of a material (substantial) product - its informational alter ego - that is fundamentally important, at all stages of its formation in the context of the advanced supply chain, the central link of which is a manufacturing enterprise that forms the basis of consumption value of the created product.

In turn, the logistics - process-data flow approach to organizing the activities of a production enterprise - requires understanding of such [activity] as a complex system flow process, which should be considered from both sides, technological and economic. This provision in the context of this paper requires an extensive comment.

On the one hand, production is a process of technological transformation of resources, objects of labor into the finished product. On the other hand, production is a process of economic transformation, which, in turn, is characterized by two components: costly and efficient (value). Thus, from an economic point of view, production is a process of implementation and accumulation of resource costs in order to obtain the material result - a product intended for further consumption, and thus the further costs implementation. In other words, there is the imputation of the resources value of the newly created value in the general process of production activity of the enterprise.

Therefore, the production is a continuous transformation of the material flow of labor objects, which, "penetrating" the enterprise, manifests itself in various forms of representing value, namely: at the input - in the resource, at the output - in the product.
The resource form of value presentation arises at the stage of consumption - in the sphere of consumption both industrial and final. The resource form of value means its purpose and readiness for consumption.

The form of the product manifests as a result of the resources consumption - the finished product - in the process, at the stage of production.

Along with the resource and product there is the third form - commodity. The latter is inherent in the value in the field of circulation of factors in the market and the commodity market at all stages of the logistics flow.

It should be noted that the economic content of the material flow is a continuous sequence of transitions from one form of value representation to another and specifies the presence of various stages of flow in the value creation system, in each of which there is a new source of the cause of movement and a new subject demanding and initiating the movement - one or another value chain as the basis of the formed supply chain.

The sequence of stages of the material flow transformation in the structure of the reproductive cycle is represented by the following transformation processes:

- the factors market presents the following production factors in the commodity form: labor, land and capital (in physical form), which are already presented in the resource form and appear, respectively, as labor, production and capital resources when entering the enterprise. In the production process, direct labor when using means of labor effects on the objects of labor, as a result of which the latter are converted into the finished products that means the transformation of the form of value presentation at this stage from resource to product one;

- finished products, depending on the purpose (for production or final consumption) enter either the market of production factors or the product market respectively. Final consumption goods become a resource for the end user; reproducing its ability to labour, which being offered in the factors market as a commodity becomes a labor resource in the enterprise. In turn, production goods become the capital resource (embodied labour) of production.

The content of the logistics approach to a vertically integrated organization of the production enterprise activity as a value chain (competitive advantage) in the structure of the value system lies in the fact that all stages of the reproduction cycle: material and technical support, production, sales are considered as a single and continuous logistics process of technological and economic transformation expressed by the reproductive chain of moving the material flow and supporting information.

Therefore, the production logistics calls for "external" vertical functional integration with the activity for providing the material resources on the one hand, and marketing activities on the other, which forms the interfunctional integrated space of the enterprise production activities. 
As already noted, the economic transformation is characterized by two components: cost and effective (value). In other words, economically the production is the process of imputation of the resources value of the newly created value in the general process of production activity of the enterprise.

This interpretation of economic transformation requires an exact understanding of its components. The effective component is nothing but a finished product that is the value created by the enterprise. The cost component is the consumed resources in the production process, the value of which is charged with a newly created value of the product. The costs as the central category of economic transformation of manufacturing enterprise flow are subject to further breakdown taking into account the role of the processes where they are involved [1].

Thus, material flow is the basis of both technological and imputed economic transformation in the process of reproduction of both values itself and the respective relations.

The importance and significance of saving (all other things being equal) costs is largely due to the fact that in the process of reproduction of value there is also a cyclic process of costs reproduction (multiplicative increase).

In this context, it should be particularly emphasized that one of the most important tasks is the cost management task specifically carried out in the controlling system. In the classic form, the cost management cycle consists of five successive stages:

- determination of value for the user;

- calculation of acceptable costs;

- determination of the current costs of the value flow;

- calculation of the target costs of the value flow;

- bridging of a gap between the current and the desired status.

Currently, the most problematic stage in domestic enterprises is the stage of determining the current costs of the value flow due to systemic issues in arrangement of accounting the generated cost flow. First of all, this applies to enterprises of batch and mass production. The main reasons can be called the following: inaccurate compliance with the accrual principle when accounting, allocating the overhead and non-manufacturing costs, uneven distribution of resources, mainly labor, due to irrational planning of production processes, significant delay in costs reflection in relation to the fact of their event.

Controlling aimed at the implementation, on the one hand, of informational and methodological support of management, and, on the other hand, of continuous breakdown, implementation, and control of management decisions fulfilment is called upon not only in the presented context to build a management accounting system that allows adequate and accurate identification of the cost flow structure, but also form the tools for preparation, justification and adoption of effective decisions.

The blockchain technologies are promising in terms of solving these (and not only) problems, which allow to form a single tracking chain at all stages of formation of specific value (resource-product-goods) by accurate real time recording all resulting events. Moreover, the data is open for all participants in the chain, which presents great opportunities for clear arrangement of not only accounting, but also comprehensive analysis of the costs involved.

It should be particularly emphasized that the key task of the intermediaries / suppliers / vendors included in the supply chain structure is to impute to consumers the adequacy of perception of the commodity form of the supply proposal of the need for a real resource, which also identifies their logistics functionality: providing specific users with the necessary goods of appropriate quality in the required quantity (required structure ) at the exact time in the right place with the least (all other things being equal) costs.

Therefore, the digital technologies determine the ability of participants in the supply chain to adequately and timely respond to changes in consumer demands, on the one hand, and, on the other hand, at the same time they become an effective tool for users themselves (both industrial and final), providing the ability to accurately and quickly, timely manifest and satisfy their value requests and preferences.

In the above context we can agree with the structure of the relevant five key areas of the economic space for forming and implementing the strategic positioning of economic entities: user (customer), value, innovation, information and really competitive [9].

Currently, the structure of the user area at the stage of digital transformation, in addition to the known ones, is characterized by another additional significant factor - the network nature of users' organization that determines their mutual influence and interaction between each other, on the one hand, and their relations with the proposal subjects, on the other, determining value orientation. The latter is also characterized by the more dynamic nature of changes both in content, and in terms, and in the time of presentation of the required value resources. This nature ensures the solution of urgent user issues.

The innovative area based on the digital technologies is characterized by new digital experimental and design capabilities for arranging the information support for the process of creating and producing the value with a minimum of call functional and technological trend expanding during its life cycle in accordance with the user needs, which (all other things being equal) also leads to decreasing material and labor costs, as well as time costs.

The information area is characterized by the expansion and structuring of the information space and providing the greater access to information resources based on digital analytical tools.

In general, it should be noted that the development of information technologies increases the level of information accessibility and the exchange rate between market participants, which leads to expansion of the geographical boundaries of product markets and an increase in the number of vendors, decrease in the opportunities for differentiating products and services, as well as reducing the costs for obtaining the information on the transaction and the exchange participants, and ultimately - to bring the conditions of exchange closer to the model of perfect competition and change the nature of competition: increase 
its intensity and pressure of competitive forces on in the enterprise, which weakens its position in the market.

On the other hand, the digital technologies change the nature of competition in terms of appearing a wider variety of sources of competitive advantage and their organization in the process of value creation, as well as in competition displacement from homogeneous areas to asymmetric areas, in particular in the direction of disintermediation eliminating intermediaries between vendors and buyers with the subsequent organization of new relations and supply chains.

Information technologies provide subjective, spatial and temporal variability in the organization of interaction between partners in supply chains. In particular, production network structures are being formed.

Modern production networks consist of separate independent enterprises, each of which is both a manufacturer and a consumer of resources in a certain ratio. They are united by the network organization of the integrated reproduction outline of the logistics value flow synthesizing its material and informational components. The subject of the latter is the information model of the value (product, resource) to be created: design, engineering and technological, process and organizational.

The total production information covering the entire range of created values forms a single information space of the production network specifying the real possibility of agreement and coordination of the objectives of network entities and organization of the value creation process management. The providers of a single information space are the so-called industrial centers that concentrate systemic production information - a kind of depository of digital projects and production models - distributed in the economic space and interconnected by such a higher level, which makes it possible to expand its [market space] coverage and more accurate compliance with user requests.

The digital transformation determines the dynamics of expanding the information space of production, which is expressed through the following: the accuracy of production information modeling as a whole and its individual components is complicated and increased; the field of production information modeling is expanded, covering the entire life cycle of the created value (product-goodsresource) - from creation-designing to implementation and consumption; the information model (mock-up) is a complete (at a certain stage of the life cycle) information reflection of the real value (product, resource) to be produced.

The cooperative form of arranging the value creation in the production networks makes it possible to create it at the level of the advanced technological standards. In turn, the logistic approach to the production organization ensures the implementation of the functional accuracy of compliance with the user needs.

The following circumstance should be noted: there is a dichotomy of information and real (material, substantial) forms of value representation. The first one becomes an independent product and takes a marketable form in the contracting process. Its circulation area is the internal reproductive outline of the production network; the main consumption entities are the network enterprises.

In this regard, it is important to emphasize another circumstance: the inalienability of the information product (resource) from the manufacturer-vendor in the contracting process, which determines the triad of logistics flow components (material, information and legal) and creates the need for certain legal decisions taking into account the dynamic nature (uncertainty of the term actions) of the life cycle of the production networks themselves.

Fulfillment of the mission for satisfying the resources need is determined by the target orientation of the production network to create competitive superiority due to the following: joint nature of formation and implementation of the competitive strategy and policy by network partners (the common goal is the result ("product") of matching the goals and interests of the latter in the overall dynamic process of joint activities in value creation); orientation to a highly intellectual level of advanced innovative achievements in the field of technology, information and knowledge; creation, maintenance and use of a single information space as a space of information support, design and simulation of the value creation process.

The functional organization of production networks as logistics systems provides for the integration of the value chains of its individual enterprises in the two-level reproduction cycle - internal and external - of the integrated logistics value creation process (consumption resource).

The value chain is arranged as a key "organizational utility" based on correlating the structure of the main and auxiliary processes (from the point of view of competitive advantage creation) with the created value (product, resource) and requires the total coverage and penetration of the logistic approach to its [value] design and provision, production and implementation.

In the context of the Industry 4.0, the production networks fully meet the possibilities to implement the wellknown five paradigms that mean the cardinal change in the approach to production in terms of digital transformation: vertical and horizontal integration - decentralized intelligence - decentralized control - continuous digital design - cyber-physical production systems [7; 11].

Vertical integration consists in building a certain hierarchy, the various levels of which are united by special data exchange interfaces, on the basis of which the production organization and production processes management of - resource flows are carried out.

Horizontal integration consists in combining the remote network entities with the resources flow into the vertical space of their own organization, which makes it possible for real-time synchronized exchange of internal and external data in the integrated value creation process.

The decentralized intelligence means the ability of objects and means of production to exchange data on the production process necessary for decentralized management.

The decentralized management means the creation and use of distributed control systems for the production process (equipment). Both the decentralized intelligence and the 
decentralized management are carried out in the information space of the Internet of Things, the industrial Internet.

The continuous digital design means digital representation and simulation of the entire production process from the design to the manufacturing as an integrally dual physical process.

Finally, the cyber-physical production system means a relatively self-contained, within certain limits, physical feedback self-control of the production process based on "smart" products and equipment.

The increasing cost for meeting growing consumer demands, increase of opportunity costs to meet growing demand; increasing tendency to economical consumption, strengthening a pragmatic approach to consumption request the use of resource-saving ("smart") technologies, which are not limited to digital ones. The organizational and managerial ones should be added to the above, which are based on new conceptual approaches: social production, decentralized production; production in the mode of a continuous technological cycle, etc.

Social production (entrepreneurship) is not limited to the framework of only industrial production structures, but involves the users, including end ones, in the technological process.

The production decentralization is an alternative to a centralized hierarchical organization of production that provides economic benefit as a result of scale, but requires large investments, and also lacks the necessary flexibility at present. The decentralized production concept is focused on the creation of distributed horizontal networks that bring production closer to both local sources of resources and locally concentrated users. The implementation of this concept provides for the organization of economic relations and management decentralization not only in the field of final consumption (B2C), but also production (B2B) in terms of substantial range of resources including energy ones.

The factor of production geo distance from real and potential users determines both the time lag between production and consumption, and the effect of costs increasing (respectively, prices) in supply chains. A similar phenomenon of costs increasing is compounded by the need to create and maintain a certain structure of inventories, both for the above reasons, and in order to ensure an operational response to changes in demand. As a whole, the influence of the presented factors leads to the so-called cost gap between the final (retail price in the field of final consumption) and the product / resource value in the user assessment.

The general tendency of resource saving and profitability (all other things being equal) of industrial production on a global scale (space) is expressed in the following:

- return of industrial production from home countries to the environment of national economies. A sharp increase in transport and logistics costs overrides savings on relatively cheaper labor, which costs, in turn, also show a tendency to increase;

- organization of cost-effective provision of the marginal user zone by including directly local consumers in the supply chain as intermediaries;
- identification, use and development of local resources. In combination with other factors of production efficiency, the emphasis on the use of local resources leads to savings in logistics costs, as well as flexibility, efficiency and continuity of the industrial production cycle;

- Shared use of production capacities, resources and logistics infrastructure of supply and distribution networks. Distribution of the economy experience of joint corporate consumption at the inter-corporate level and over allows achieving savings (all other things being equal) firstly on shared use of transport and logistics infrastructure of supply and distribution networks;

- formation and use of the integrated system of supply-support, production and market. The integration is not limited solely to additive combination of the completed listed stages with their separate management into a single process, but involves their hybrid combination in time and space to reduce the total cycle of users provision in accordance with the strategic concept of deferred differentiation, which provides flexible, timely and maximumly accurate match their [users] needs;

- organization of information support at the level of real time breakdown of complex local demand components. Subject, specific and on-line information about the local projection of the "basic logistics rules" set is a factor in the economical, timely, accurate and saving (all other things being equal) provision of the local needs of specific users. In this case, the organization of information support shall cover not only the chain, but the entire value system, including suppliers and intermediaries.

The main trends of digital transformation influence on production are presented in Table 1.

TABLE I. THE EFFECT OF DIGITAL TECHNOLOGIES ON PRODUCTION ORGANIZATION

\begin{tabular}{|l|l|}
\hline \multicolumn{1}{|c|}{ Technology } & \multicolumn{1}{|c|}{ Production Effect } \\
\hline Cloud technologies & $\begin{array}{l}\text { Concentration of system production information } \\
- \text { digital projects and production models; } \\
\text { expanding the area of information simulation of } \\
\text { production covering the entire life cycle of the } \\
\text { created value (product-goods-resource) }\end{array}$ \\
\hline Big Data & $\begin{array}{l}\text { Improving the accuracy of information } \\
\text { simulation of production as a whole and its } \\
\text { individual components }\end{array}$ \\
\hline Industrial Internet & $\begin{array}{l}\text { Formation of the single information space of the } \\
\text { production network, decentralized management } \\
\text { of the production process (equipment) }\end{array}$ \\
\hline technologies & $\begin{array}{l}\text { Decentralization of the database control system } \\
\text { providing, on the one hand, protection against } \\
\text { unauthorized access, and, on the other hand, } \\
\text { clear, transparent for all interested parties, real- } \\
\text { time representation of the entire life cycle of the } \\
\text { specific created value }\end{array}$ \\
\hline Additive production & $\begin{array}{l}\text { Increase of product accessibility for users, } \\
\text { accuracy of product compliance with user needs }\end{array}$ \\
\hline
\end{tabular}

Thus, the presented provisions show a sufficiently significant multidisciplinary influence of digital technologies on the information space of production enterprises, which 
leads to the new forms of interaction with partners in the structure of supply chains included in the reproduction cycle.

\section{CONCLUSION}

The above allows drawing the following conclusion. The effect of digital technologies for production management, organization of interaction between participants in supply chains, the generation of which, in turn, is included in the reproductive cycle system, is significant.

First, the digital technologies becomes a factor in the competitive development and competitive recovery of production enterprises (which are subjects of certain supply chains), providing primarily and mainly qualitative informational interaction between subjects of the economic environment - various levels, scales and positioning built according to emerging needs and preferences.

Secondly, the logistics approach to management implemented with the active use of modern digital technologies, allows minimizing the economic gap between the commodity form of supply and the resource form of the real needs of business units at all stages and levels of the reproduction process. A clear understanding of the content of transformation of the material flow that permeates the supply chain of industrial enterprises is the basis for the formation of an information product as a material product prototype which leads to identification of reserves for reducing the costs and increasing the consumer value of the created product proposed as the goods to the customers.

Thirdly, the digital technologies transforms the actual economic space for positioning participants in the supply chains, which ultimately manifests in changing the nature of competition and modifying the structure of supply chains. As a result, on the one hand, there is the possibility of forming the production networks that radically change approaches to arrangement of production and exchange in conditions of digital transformation, and, on the other hand, determine the possibility of extremely accurate execution of the seven key logistics rules.

At the same time, one should not minimize and all the more ignore to a certain extent complication of the conditions for enterprise functioning in the market and the increasing the pressure of competitive forces due to change in the information environment that also predetermines changing of its competitive behavior and positioning.
The main provisions and trends of transformation processes in the economy given in this article require further research and development regarding the possibility of the effective use of appropriate tools in arrangement of the economic space.

\section{REFERENCES}

[1] V.K. Kozlov, E.S. Tsareva, D.K. Filosofova, "Economic content of the logistics flow: accounting and analysis" Logistics and Supply Chain Management, Moscow, 2017, No. 3 (80), pp. 57-62.

[2] N.K. Moiseyeva, Economic basis of logistics: Textbook, Moscow: INFRA-M, 2008.

[3] A.A. Chebotaev, D.A. Chebotarev, Logistics - synergistic, quality service in the price of the supplied commodity resources: Textbook / Moscow: JSC "Publishing House "Ekonomika", 2009.

[4] V.S. Sizov, Strategic management of the reproductive process, Moscow: Economis, 2004

[5] Sh.M. Valitov, Management of competitive advantages in conducting the industrial policy, Moscow: Publishing House "Ekonomika", 2010.

[6] Ya. Gibson, D. Rosen, B. Stacker, Adaptive production technologies, Moscow: TEKHNOSFERA, 2016.

[7] A.I. Levina, A.D. Borremans, A.N. Burmistrov. Features of enterprise architecture designing of infrastructure-intensive companies (2018) Proceedings of the 31st International Business Information Management Association Conference, IBIMA 2018, pp. 4643-4651.

[8] Industrial policy in the economy digital transformation era: monograph, coll. of authors; edited by S.A. Tolmacheva, Moscow: KNORUS, 2018.

[9] D.L. Rogers, Digital transformation. Practical Guide, trans. from English, Moscow: Publishing group "Tochka", 2017.

[10] "Smart" environments, "smart" systems, "smart" production: a series of reports (green books) in the framework of the project "Industrial and Technological Foresight of the Russian Federation", $4^{\text {th }}$ ed., St. Petersburg: Fund "Center for Strategic Research "North-West", 2012.

[11] I. Ilin, A. Grigoreva. How stakeholders make decision about changes in enterprise architecture. Cases in private business and public organization (2017) CEUR Workshop Proceedings, 2018, pp. 50-62.

[12] M.Yu. Sheresheva, Forms of network interaction between companies: education guidance, Moscow: Publishing house of state university Higher School of Economics, 2019.

[13] V.V. Ovchinnikov, Global competition in the mixed economy era, Moscow: Institute of Economic Strategies, 2007.

[14] V.V. Ovchinnikov, Global Competition Technologies, Moscow: Institute of Economic Strategies, International Academy of Future Research, 2012.

[15] I.D. Afanasenko, V.V. Borisova, Digital logistics: a textbook for students of economic specialties of all forms of training, St. Petersburg: Peter, 2019. 